\title{
Analysis of the Cryptosporidium spp. and gp60 subtypes linked to human outbreaks of cryptosporidiosis in England and Wales, 2009 to 2017
}

Rachel M. Chalmers ${ }^{1,2^{*}}$, Guy Robinson ${ }^{1,2}$, Kristin Elwin ${ }^{1,2}$ and Richard Elson ${ }^{3,4}$

\begin{abstract}
Background: Cryptosporidium spp. are important causes of gastroenteritis that can be transmitted from humans and animals. We elucidated the distribution of species and gp60 subtypes in human outbreaks classified by transmission vehicle.

Methods: We used a combined database of national outbreak surveillance and reference unit data to analyse outbreaks by setting, vehicle, season, and linkage with suspected sources.

Results: A total of 178 outbreaks involving 4031 laboratory confirmed cases were identified; 82 (46\%) outbreaks involved recreational waters, 74 (42\%) animal contact, 4 (2\%) environmental contact, 4 (2\%) person-to-person spread, 3 (2\%) food, 2 (1\%) drinking water supplies, and $9(5 \%)$ were of unknown source. The infecting Cryptosporidium sp. was identified in 131 (74\%) outbreaks; 69 were C. parvum, 60 C. hominis, and in two outbreaks cases were infected with either species. Animal contact, environmental contact, and food-borne outbreaks were exclusively C. parvum and were mainly in first half of the year. Recreational water outbreaks were predominantly C. hominis and were mainly in the second half of the year. Outbreaks attributed to person-to-person spread were exclusively C. hominis and all occurred in October. Both C. parvum and C. hominis caused drinking waterborne outbreaks. Gp60 subtypes were identified from patients in 48 C. parvum and 38 C. hominis outbreaks, revealing more subtypes among C. parvum $(n=14)$ than C. hominis $(n=7)$ outbreaks. Cryptosporidium hominis IbA10G2 predominated (30 outbreaks). Of C. parvum subtypes, IlaA15G2R1 predominated (17 outbreaks), followed by llaA17G1R1 (12 outbreaks), IlaA19G1R1 (four outbreaks), and other subtypes caused three or fewer outbreaks each. Linkage between cases and suspected sources by gp60 subtype was established in nine animal contact, three swimming pool, and one drinking water outbreak.

Conclusions: The public health benefit of identifying infecting species and subtypes was twofold: (i) identifying and strengthening epidemiologic links between cases; and (ii) indicating possible exposures and sources to inform outbreak management. Gp60 subtype refined the epidemiological investigations, but a multilocus genotyping scheme would provide further benefit. Characterisation of Cryptosporidium spp. and subtypes needs to shift from predominantly supporting outbreak investigations to becoming nationally systematic.
\end{abstract}

Keywords: Cryptosporidium parvum, Cryptosporidium hominis, Outbreak, Surveillance, gp60

\footnotetext{
*Correspondence: rachel.chalmers@wales.nhs.uk

${ }^{1}$ Cryptosporidium Reference Unit, Public Health Wales Microbiology

and Health Protection, Singleton Hospital, Swansea SA2 8QA, UK

Full list of author information is available at the end of the article
} 


\section{Background}

The gastrointestinal parasitic protozoans Cryptosporidium spp. are notifiable as causative agents of human infection in England and Wales [1]. Live laboratory reporting by diagnostic laboratories is used to collect case data and enable national surveillance by Public Health England (PHE). Numbers are variable and seasonal; 2990 to 5925 cases (mean 4341 cases) were reported annually in the years 2007-2016, with most cases in the late summerearly autumn [2]. Identification of large-scale outbreaks is based on active exceedance monitoring, and on syndromic surveillance (diarrhoea, vomiting) [3]. Practices for local exceedance monitoring, outbreak investigations and reporting vary [4], and outbreak surveillance is based on voluntary reporting; data are collated by PHE using the Outbreak Electronic Foodborne and Non-Foodborne Gastrointestinal Outbreak Surveillance System (eFOSS). Upon notification of an outbreak, a link to a web-based standardized surveillance form is sent to the lead investigator for completion once the outbreak investigation has ended.

Cryptosporidium outbreaks reflect the faecal-oral transmission, robustness, and chlorine resistance of this parasite, and have been linked to recreational waters (especially swimming pools), mains and private drinking water supplies, institutions such as hospitals and children's day-care centres, food consumption, animal contact, and various environmental exposures [5]. Outbreak investigations are hampered somewhat as the incubation period is usually 5 to 7 days but can be up to 2 weeks, and by the time an outbreak is recognised recall is difficult and sampling suspected sources may not be possible or helpful. The only standard methods are for testing water $[6,7]$, leafy green vegetables and soft berry fruits [8].

Routine laboratory testing identifies the genus Cryptosporidium; species differentiation is a specialist or reference laboratory test and at a global scale is not widely available. Where it has been done, most human cases and outbreaks are caused by either Cryptosporidium parvum which has a wide host range including livestock, or Cryptosporidium hominis which is human-adapted [9]. People-related exposure, environmental and social risk factors have been identified epidemiologically for $C$. hominis whereas those for C. parvum are mainly animalrelated $[10,11]$. Species identification therefore provides a useful differentiation between human and zoonotic sources [12], and since January 2000 has been undertaken on Cryptosporidium-positive stools voluntarily submitted to the national Cryptosporidium Reference Unit (CRU) and, where possible, on positive samples from suspected sources or vehicles of infection, as part of services provided for case and outbreak investigation, management and control in England and Wales [13].
Since 2003 further characterisation of C. parvum and $C$. hominis has been undertaken at the CRU by sequencing part of the hyper-variable $60 \mathrm{kDa}$ glycoprotein $(g p 60)$ gene [14]. The nomenclature of gp60 genotypes has been described in detail $[9,15,16]$ and is illustrated in Fig. 1. Where gp60 genotypes have been investigated in human cryptosporidiosis in Europe, IbA10G2 is the most common among $C$. hominis and IIaA15G2R1 usually, but not always, the most common among C. parvum [5]. Identifying the gp60 genotypes has been an important supplement to epidemiological and environmental data in characterising the infection/contaminants in outbreaks, relating transmission vehicles, and linking cases [9]. Previous analysis of waterborne outbreaks that occurred in England and Wales between January 2001 and December 2010 demonstrated strengthening of the evidence for the association with water provided by identifying the Cryptosporidium species and gp60 subtypes, as well as monitoring the spread of outbreak-associated strains [17]. Likewise, in animal contact-related outbreaks analysed between 1999-2008, animals were linked by $g p 60$ subtype to human cases in three outbreaks [18]. Here, we provide an updated overview of the Cryptosporidium species and gp60 genotypes associated with outbreaks in England and Wales from January 2009 to December 2017, ahead of the introduction of a validated multilocus genotyping scheme.

\section{Results}

A total of 178 Cryptosporidium outbreaks were identified in England and Wales in the years 2009-2017 (Table 1); 123 (69\%) had been reported to eFOSS, 43 of which were unique to that dataset. Of the 135 outbreaks in the CRU database, 55 had not been reported to eFOSS. Stools were sent to the CRU for speciation, in 131 outbreaks. Of the 178 outbreaks, 82 (46\%) involved recreational waters, $74(42 \%)$ animal contact, $4(2 \%)$ environmental contact or outdoor recreation, 4 (2\%) person-to-person spread, 3 (2\%) food, 2 (1\%) drinking water supplies, and $9(5 \%)$ outbreaks with unknown or various exposures (Table 1). Comparison of the outbreaks unique to each dataset showed that there was no significant difference in the proportion of animal contact outbreaks $\left(\chi^{2}=0.63\right.$, $P=0.43)$ or recreational water outbreaks $\left(\chi^{2}=0.41\right.$, $P=0.52$ ) (data not shown); therefore, a combined database of all 178 outbreaks was used.

The number of confirmed cases was known for 172 outbreaks, affecting a total of 3854 cases, median 5 (range 2-1589) per outbreak. Of the outbreaks with a known vehicle or source, the food-borne outbreaks had the most cases (Table 1).

The Cryptosporidium species infecting patients were identified in 131 (74\%) of outbreaks (Table 1), as 


\section{Overview of the gp60 gene:}

First an allelic "family" is identified from the sequence of a conserved region. Variation in a trinucleotide repeat region then identifies subtypes within each family. Finally, single or contiguous copies of a repetitive sequence, $\mathrm{R} n$, or variations thereof, may be present in some gp60 families: in C. hominis la the repetitive sequence is AA(A/G)ACGGTGGTAAGG and the last repeat is always AAAACGGTGAAGG, and in $C$. parvum lla the repetitive sequence is ACATCA.

\begin{tabular}{|c|c|c|c|c|}
\hline \begin{tabular}{l}
\multicolumn{1}{c}{5} \\
primer \\
region
\end{tabular} & $\begin{array}{l}\text { Trinucleotide } \\
\text { repeat region: } \\
\text { Counts of } \\
\text { TCA / TCG / } \\
\text { TCT repeats } \\
\text { after the allele } \\
\text { family name }\end{array}$ & $\begin{array}{c}\text { Repetitive sequence(s): } \\
\text { The number of contiguous } \\
\text { copies of a short repeat } \\
\text { sequence } \\
\text { Rn at the end of the } \\
\text { subtype name }\end{array}$ & $\begin{array}{l}\text { Conserved region: } \\
\text { Sequence defines the } \\
\text { allelic family } \\
\text { la, Ib, Ic etc. in C. hominis } \\
\text { Ila, Ilb, Ilc etc. in } C \text {. parvum }\end{array}$ & $\begin{array}{c}3^{\prime} \\
\text { primer } \\
\text { region }\end{array}$ \\
\hline
\end{tabular}

\section{Examples:}

\section{C. hominis $\mathrm{Ib} \mathrm{A} 10 \mathrm{G} 2$}

\begin{tabular}{|l|l|c|c|l|}
\hline & $\begin{array}{c}\text { TCA } n=10 \\
\text { TCG } n=2 \\
\text { TCT } n=0\end{array}$ & $\begin{array}{c}\text { Repetitive sequence is } \\
\text { absent }\end{array}$ & Conserved region: & \\
& Sequence matches $\mathrm{lb}$ & \\
\hline
\end{tabular}

\section{TCATCATCATCATCATCATCATCGTCATCATCGTCA}

$\begin{array}{llllllllllll}1 & 2 & 3 & 4 & 5 & 6 & 7 & & 8 & 9 & & 10\end{array}$

\section{C. hominis laA14R3}

\begin{tabular}{|l|c|c|c|c|}
\hline & $\begin{array}{c}\text { TCA } n=14 \\
\text { TCG } n=0 \\
\text { TCT } n=0\end{array}$ & $\begin{array}{c}\text { Repetitive sequence } \\
\text { AA(A/G)ACGGTGGTAAGG } \\
n=3\end{array}$ & $\begin{array}{c}\text { Conserved region: } \\
\text { Sequence matches la }\end{array}$ & \\
\hline \multicolumn{7}{|c|}{$\begin{array}{l}\text { AAGACGGTGGTAAGG-AAGACGGTGGTAAGG-AAAACGGTGAAGG } \\
1\end{array}$} \\
\hline
\end{tabular}

\section{C. parvum IlaA15G2R1}

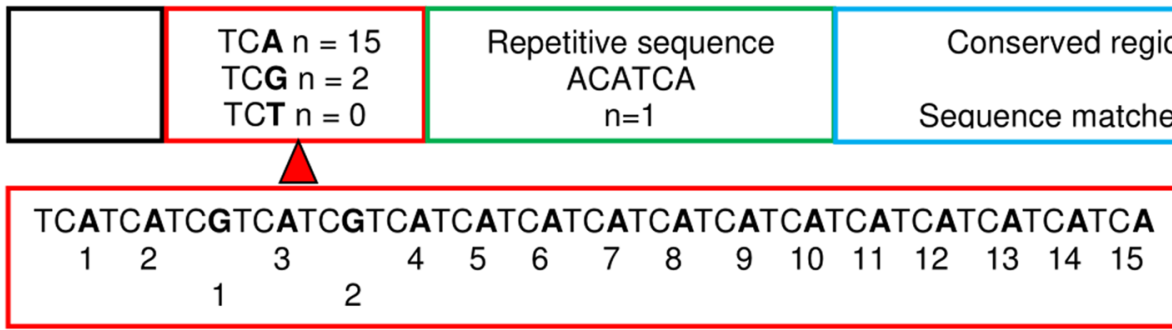

Fig. 1 Derivation of gp60 nomenclature for Cryptosporidium hominis and C. parvum 
Table 1 Outbreak vehicles and Cryptosporidium species identified in cases in England and Wales, 2009-2017

\begin{tabular}{|c|c|c|c|c|c|c|}
\hline \multirow[t]{2}{*}{ Vehicle or source (median; range) ${ }^{\mathrm{a}}$} & \multirow[t]{2}{*}{ Setting } & \multicolumn{5}{|c|}{ Number of outbreaks } \\
\hline & & Total & No. genotyped (\%) & C.parvum & C. hominis & Both species \\
\hline All outbreaks (5; 2-1589 cases) & & 178 & $131(74)$ & 69 & 60 & 2 \\
\hline \multirow[t]{5}{*}{ Recreational water (5; 2-70 cases) } & & 82 & $59(72)$ & 6 & 52 & 1 \\
\hline & Swimming pool & 72 & 55 & 6 & 48 & 1 \\
\hline & Hydrotherapy pool & 5 & 1 & 0 & 1 & 0 \\
\hline & Baby swimming pool & 4 & 2 & 0 & 2 & 0 \\
\hline & Paddling pool (outdoor) & 1 & 1 & 0 & 1 & 0 \\
\hline \multirow[t]{6}{*}{ Animal contact (5; 3-41 cases) } & & 74 & $53(72)$ & 53 & 0 & 0 \\
\hline & Open/petting/educational farm & 52 & 38 & 38 & 0 & 0 \\
\hline & Commercial farm & 7 & 4 & 4 & 0 & 0 \\
\hline & College farm events & 8 & 5 & 5 & 0 & 0 \\
\hline & Student animal handling classes & 5 & 4 & 4 & 0 & 0 \\
\hline & Lambs taken to institutions & 2 & 2 & 1 & 0 & 0 \\
\hline \multicolumn{7}{|l|}{ Environmental contact (7; 5-14 cases) } \\
\hline & Environmental contact & 4 & $3(75)$ & 3 & 0 & 0 \\
\hline \multicolumn{7}{|c|}{ Person-to-person spread ( $5 ; 3-14$ cases) } \\
\hline & Daycare nursery & 4 & $3(75)$ & 0 & 3 & 0 \\
\hline \multirow[t]{3}{*}{ Drinking water } & & 2 & $2(100)$ & & & \\
\hline & Mains water supply (23 cases) & 1 & 1 & 0 & 1 & 0 \\
\hline & Private water supply (12 cases) & 1 & 1 & 1 & 0 & 0 \\
\hline \multirow[t]{4}{*}{ Food } & & 3 & $3(100)$ & & & \\
\hline & Ready-to-eat salad (300 cases) & 1 & 1 & 1 & 0 & 0 \\
\hline & Milk (6 cases) & 1 & 1 & 1 & 0 & 0 \\
\hline & $\begin{array}{l}\text { Sandwiches containing salad; } \\
\text { coffee shop (192 cases) }\end{array}$ & 1 & 1 & 1 & 0 & 0 \\
\hline \multirow[t]{5}{*}{ Not known (20; 4-1589 cases) } & & 9 & $8(89)$ & 3 & 4 & 1 \\
\hline & Community & 4 & 3 & 1 & 1 & 1 \\
\hline & Not known & 3 & 3 & 3 & 0 & 0 \\
\hline & School & 1 & 1 & 1 & 0 & 0 \\
\hline & Open prison & 1 & 1 & 1 & 0 & 0 \\
\hline
\end{tabular}

${ }^{a}$ Median number of confirmed cases; range, where known

samples were not always sent for genotyping. More outbreaks were caused by C. parvum $(n=69)$ compared to C. hominis $(n=60)$. In two outbreaks, patients infected with either species were identified. $G p 60$ subtyping was undertaken in 86 outbreaks. The C. parvum outbreaks involved 14 gp60 subtypes compared to 7 in the C. hominis outbreaks (Fig. 2). The itemised list of outbreaks can be viewed in Additional file 1: Table S1.

The distribution of outbreaks by vehicle varied seasonally (Fig. 3), with animal contact outbreaks predominating in the first half of the year and recreational water outbreaks mainly in the second half of the year. Outbreaks involving person-to-person spread were all in October, and both drinking water outbreaks were in April.

Of the 74 animal contact outbreaks, the Cryptosporidium species infecting patients was identified in 53 (72\%); all were C. parvum. Gp60 subtypes were investigated in 35 animal contact outbreaks, and 9 subtypes were identified; IIaA15G2R1 and IIaA17G1R1 were most common (Fig. 2a), and although both are widely distributed globally [9] IIaA17G1R1 has only been reported in one outbreak previously which was also in the UK [18]. Two outbreaks were caused by IIaA18G2R1 and although there are numerous reports in cattle and this subtype was previously linked to calf contact [18], lambs were implicated epidemiologically in both the outbreaks here and were found to be shedding this subtype in one of the outbreak investigations (Table 2). Despite IIaA15G1R1 being the most common subtype in clusters of cases and outbreaks in Scotland [19], it was involved in just two outbreaks in England and Wales, one linked to milk, and the other to animal contact with IIaA20G3R1 which previously caused 

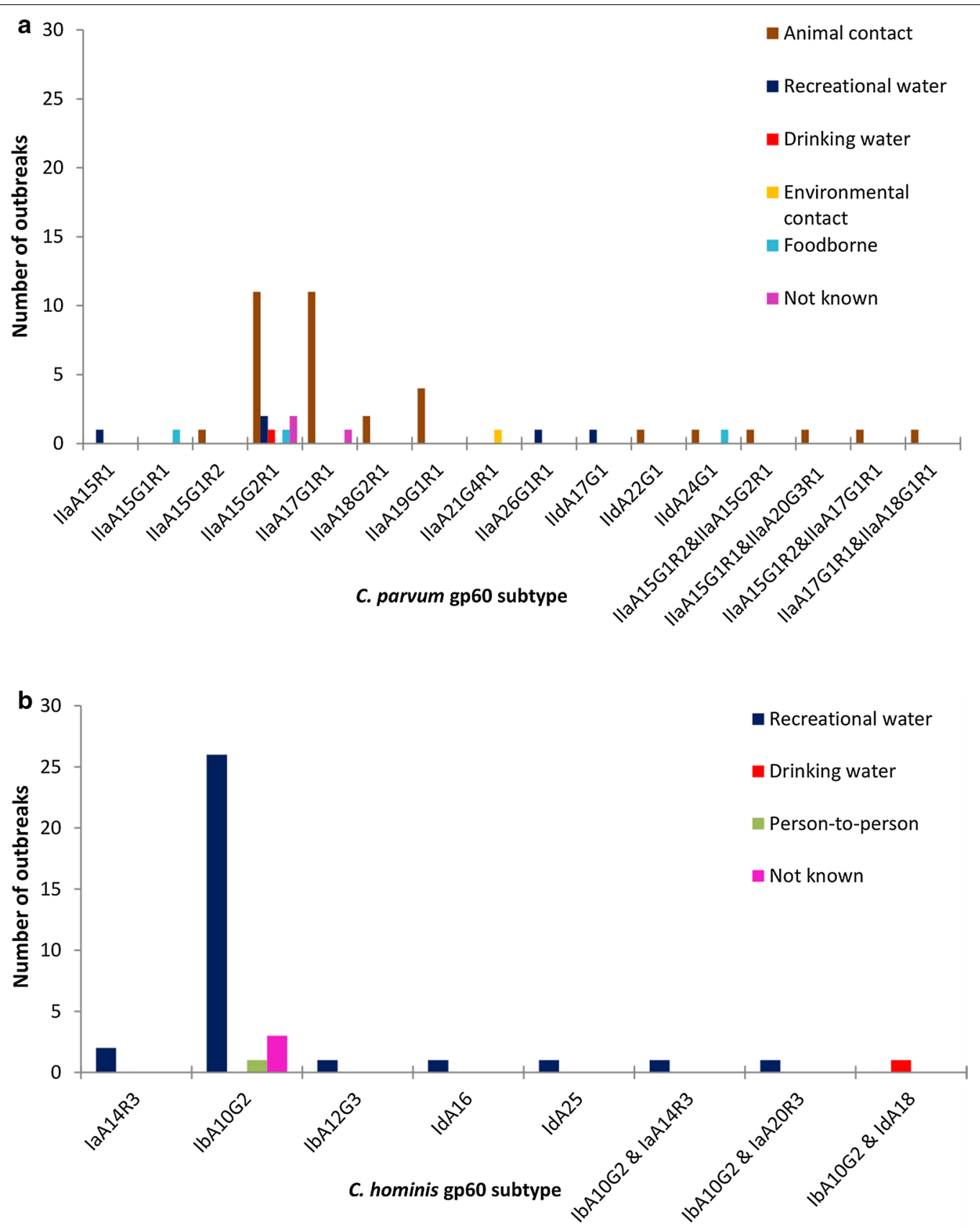

Fig. 2 gp60 subtypes identified in 86 Cryptosporidium outbreaks in England and Wales, 2009-2017. a Subset of 48 C. parvum outbreaks. b Subset of 38 C. hominis outbreaks

an outbreak in south-east Ireland linked to a public drinking water supply [20]. In three other outbreaks, two subtypes were also identified in different patients (Fig. 2a), indicating that there may have been contact with different animals at the same setting or that animals were co-infected. In four outbreaks, IIaA19G1R1 was identified but in one of these outbreaks all nine case samples had a nonsynonymous substitution in the gp60 sequence (adenine to guanine transition at nucleotide 191, see GenBank accession number MK391452) which altered the amino acid sequence, changing the aspartic acid residue to a glycine residue. This substitution 


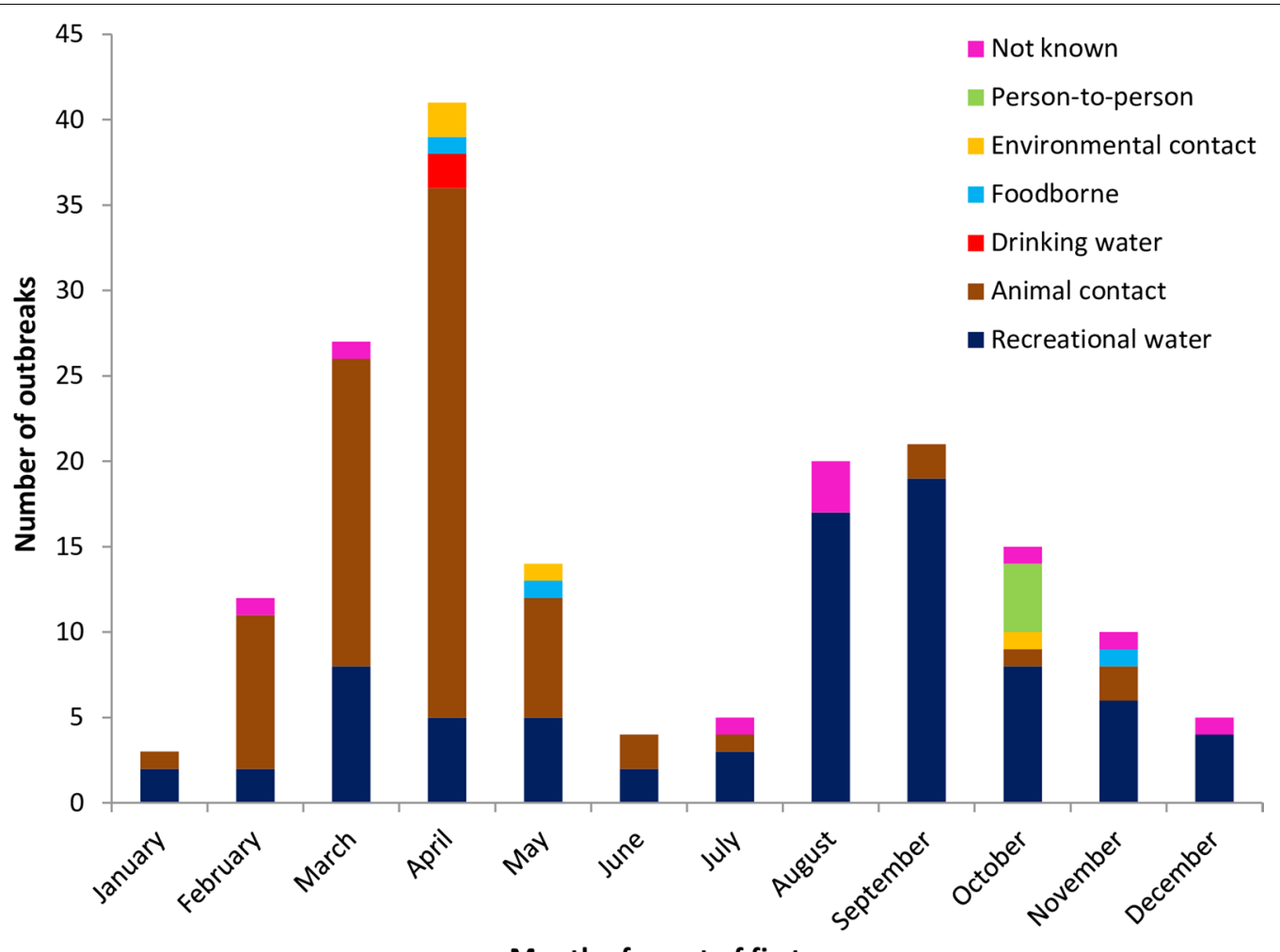

Month of onset of first case

Fig. 3 Seasonal distribution of Cryptosporidium outbreaks England and Wales 2009-2017

has been reported previously elsewhere, but the impact upon the resultant glycoprotein is unknown.

Most of the other C. parvum subtypes found in animal contact outbreaks (Fig. 2a) have been only reported previously in sporadic cases and animals, but food-borne and animal contact outbreaks caused by IIdA24G1 have been reported in Sweden [21, 22].

In $12(16 \%)$ animal contact outbreaks, C. parvum was also confirmed in animals and the same gp60 subtypes found in patients were identified in nine of these, providing further microbiological evidence for the source of the outbreak (Table 2). Lambs were most commonly implicated as sources of infection. Two farm premises were each linked to two outbreaks each within the study period (Table 2); at one farm the C. parvum subtypes differed between the two outbreaks which were 1 year apart, most likely because orphan lambs were brought in from different holdings [23]. Other Cryptosporidium species and gp60 subtypes were also detected in animal samples as part of outbreak investigations, including species considered zoonotic such as C. ubiquitum (Table 2).

Cryptosporidium parvum was also the exclusive cause of the three food-borne outbreaks. In an outbreak linked by descriptive epidemiology and environmental investigations to under-pasteurised milk from an on-farm dairy, IIaA15G1R1 was detected in patients and a calf at the farm. Analytical epidemiology (case-control studies) linked the other two food-borne outbreaks to consumption of ready-to-eat loose leaf salad in which patients were infected with IIaA15G2R1 [24], and to eating sandwiches containing salad and coffee shops which was associated with infection with a more rare subtype, IIdA24G1 [25].

The Cryptosporidium species infecting patients were identified in 59/82 (72\%) recreational water outbreaks (Table 1); of these $52 / 59$ (88\%) outbreaks were C. hominis, six were C. parvum and both these species were involved in one outbreak. All of the recreational waters were treated and most were indoor swimming pools; the only outdoor venue was a paddling pool where the outbreak was caused by $C$. hominis. In 31 recreational water outbreaks a single gp60 subtype was identified, most commonly IbA10G2 (26 outbreaks) (Fig. 2b); this subtype predominates in northern Europe [5] and has been reported in outbreaks previously in the UK [17]. Three swimming pool-related outbreaks involved IaA14R3, which was reported to have caused an outbreak in the US linked to a water park in 2001 [9]. Of the other $C$. hominis subtypes detected, IaA20R3 caused an outbreak in the USA in 2008 [9] but IbA12G3, IdA16, and IdA25 
Table 2 Subset of 25 outbreaks where Cryptosporidium was recovered from a suspected source or vehicle

\begin{tabular}{|c|c|c|c|c|c|c|c|}
\hline $\begin{array}{l}\text { eFOSS reference } \\
\text { or outbreak } \text { number }^{a} \\
\text { [publication] }\end{array}$ & Region & Year & $\begin{array}{l}\text { Month } \\
\text { of onset } \\
\text { of first case }\end{array}$ & Setting & $\begin{array}{l}\text { No. of cases } \\
\text { (lab- } \\
\text { confirmed) }\end{array}$ & $\begin{array}{l}\text { Cryptosporidium } \\
\text { species and gp60 } \\
\text { genotype in cases }\end{array}$ & $\begin{array}{l}\text { Cryptosporidium } \\
\text { detections } \\
\text { in suspected source } \\
\text { or vehicle (species } \\
\text { and gp60 genotype } \\
\text { where identified) }\end{array}$ \\
\hline \multicolumn{8}{|l|}{ Recreational water } \\
\hline 2009/64 & Wales & 2009 & August & $\begin{array}{l}\text { Swimming pool } \\
\text { (leisure pool) }\end{array}$ & $106(46)$ & C.hominis & $\begin{array}{l}\text { Presumptive oocyst } \\
\text { detected in filter } \\
\text { sand }\end{array}$ \\
\hline 14 & South-East & 2009 & November & $\begin{array}{l}\text { Swimming pool } \\
\text { (leisure pool) }\end{array}$ & $15(11)$ & C.hominis & $\begin{array}{l}\text { Oocysts detected in } \\
\text { leisure pool, strainer } \\
\text { basket, and sand } \\
\text { from two filters }\end{array}$ \\
\hline $2012 / 78$ & Wales & 2012 & August & $\begin{array}{l}\text { Swimming pool } \\
\text { (leisure pool) }\end{array}$ & $23(23)$ & C. hominis & $\begin{array}{l}\text { Oocysts detected in } \\
\text { pool water }\end{array}$ \\
\hline $2014 / 25$ & South-East & 2014 & March & $\begin{array}{l}\text { Swimming pool } \\
\text { (leisure pool) }\end{array}$ & $20(14)$ & C. hominis IbA10G2 & $\begin{array}{l}\text { Oocysts detected } \\
\text { in pool water (C. } \\
\text { hominis IbA10G2) }\end{array}$ \\
\hline $2014 / 123$ & South-East & 2014 & September & $\begin{array}{l}\text { Swimming pool } \\
\text { (leisure pool) }\end{array}$ & $15(15)$ & C. hominis laA14R3 & $\begin{array}{l}\text { Oocysts detected } \\
\text { in filter sand and } \\
\text { backwash }\end{array}$ \\
\hline 151 & West Midlands & 2016 & May & $\begin{array}{l}\text { Swimming pool } \\
\text { (leisure pool) }\end{array}$ & $10(9)$ & C. hominis IbA10G2 & $\begin{array}{l}\text { Oocysts detected } \\
\text { in pool water (C. } \\
\text { hominis) }\end{array}$ \\
\hline 152 & South-West & 2016 & May & $\begin{array}{l}\text { Swimming pool } \\
\text { (leisure pool) }\end{array}$ & $25(25)$ & C. hominis IbA10G2 & $\begin{array}{l}\text { Oocysts detected in } \\
\text { pool water and fil- } \\
\text { ter sand (C. hominis } \\
\text { IbA10G2) }\end{array}$ \\
\hline $2015 / 50$ & North-West & 2015 & July & $\begin{array}{l}\text { Swimming pool } \\
\text { (club use) }\end{array}$ & $18(4)$ & $\begin{array}{l}\text { C. parvum } \\
\text { IlaA15G2R1 }\end{array}$ & $\begin{array}{l}\text { Oocyst detected in } \\
\text { filter sand }\end{array}$ \\
\hline $2012 / 80$ & South-West & 2012 & August & $\begin{array}{l}\text { Swimming pool } \\
\text { (holiday park) }\end{array}$ & $20(6)$ & C. hominis & $\begin{array}{l}\text { Oocysts detected in } \\
\text { pool water }\end{array}$ \\
\hline $2011 / 118$ & London & 2011 & June & $\begin{array}{l}\text { Swimming pool } \\
\text { (warm, for baby } \\
\text { swim lessons) }\end{array}$ & $7(7)$ & C. hominis IbA10G2 & $\begin{array}{l}\text { Oocysts detected in } \\
\text { pool water, sand } \\
\text { from two filters and } \\
\text { backwash }\end{array}$ \\
\hline 2013/86 & $\begin{array}{l}\text { Yorkshire and the } \\
\text { Humber }\end{array}$ & 2013 & July & $\begin{array}{l}\text { Paddling pool, } \\
\text { outdoor }\end{array}$ & $70(70)$ & C. hominis IbA10G2 & $\begin{array}{l}\text { Oocysts detected } \\
\text { in pool water (C. } \\
\text { hominis IbA10G2) }\end{array}$ \\
\hline \multicolumn{8}{|l|}{ Animal contact } \\
\hline $2011 / 38$ & $\begin{array}{l}\text { Yorkshire and the } \\
\text { Humber }\end{array}$ & 2011 & May & $\begin{array}{l}\text { Open farm, same } \\
\text { premises as } \\
\text { 2013/44 }\end{array}$ & $12(12)$ & C.parvum & Lambs (C. parvum) \\
\hline 2013/44 [24] & $\begin{array}{l}\text { Yorkshire and the } \\
\text { Humber }\end{array}$ & 2013 & April & $\begin{array}{l}\text { Open farm, same } \\
\text { premises as } \\
2011 / 38\end{array}$ & $45(32)$ & $\begin{array}{l}\text { C. parvum } \\
\text { IlaA19G1R1 }\end{array}$ & $\begin{array}{l}\text { Lambs (C. parvum } \\
\text { IlaA19G1R1) }\end{array}$ \\
\hline $2013 / 31$ & South-East & 2013 & March & Open farm & $18(15)$ & $\begin{array}{l}\text { C. parvum } \\
\text { IlaA15G2R1 }\end{array}$ & $\begin{array}{l}\text { Lambs and a donkey } \\
\text { (C. parvum) }\end{array}$ \\
\hline $2015 / 27$ & South-East & 2015 & January & Open farm & $10(8)$ & $\begin{array}{l}\text { C. parvum } \\
\text { IlaA15G1R2; } \\
\text { IlaA15G2R1 }\end{array}$ & $\begin{array}{l}\text { Goat kid and lambs } \\
\text { (Cryptosporidium } \\
\text { spp.) }\end{array}$ \\
\hline $2015 / 31$ & West Midlands & 2015 & April & Open farm & $30(14)$ & $\begin{array}{l}\text { C. parvum } \\
\text { IlaA17G1R1 }\end{array}$ & $\begin{array}{l}\text { Lambs (C. parvum } \\
\text { IlaA17G1R1 and } \\
\text { IlaA21G3R1) }\end{array}$ \\
\hline $2016 / 29$ & $\begin{array}{l}\text { Yorkshire and the } \\
\text { Humber }\end{array}$ & 2016 & March & Open farm & $54(33)$ & $\begin{array}{l}\text { C. parvum } \\
\text { IlaA15G1R2; } \\
\text { IlaA17G1R1 }\end{array}$ & $\begin{array}{l}\text { Calf (C. parvum } \\
\text { IlaA17G1R1); piglets } \\
\text { (C. suis); lambs (C. } \\
\text { ubiquitum) }\end{array}$ \\
\hline
\end{tabular}


Table 2 (continued)

\begin{tabular}{|c|c|c|c|c|c|c|c|}
\hline $\begin{array}{l}\text { eFOSS reference } \\
\text { or outbreak } \text { number }^{a} \\
\text { [publication] }\end{array}$ & Region & Year & $\begin{array}{l}\text { Month } \\
\text { of onset } \\
\text { of first case }\end{array}$ & Setting & $\begin{array}{l}\text { No. of cases } \\
\text { (lab- } \\
\text { confirmed) }\end{array}$ & $\begin{array}{l}\text { Cryptosporidium } \\
\text { species and gp60 } \\
\text { genotype in cases }\end{array}$ & $\begin{array}{l}\text { Cryptosporidium } \\
\text { detections } \\
\text { in suspected source } \\
\text { or vehicle (species } \\
\text { and gp } 60 \text { genotype } \\
\text { where identified) }\end{array}$ \\
\hline 2016/19 & $\begin{array}{l}\text { Yorkshire and the } \\
\text { Humber }\end{array}$ & 2016 & February & $\begin{array}{l}\text { Open farm, same } \\
\text { premises as } \\
2017 / 12\end{array}$ & $9(9)$ & $\begin{array}{l}\text { C.parvum } \\
\text { IlaA18G2R1 }\end{array}$ & $\begin{array}{l}\text { Lambs (C. parvum } \\
\text { IlaA18G2R1 and C. } \\
\text { xiaoi) }\end{array}$ \\
\hline $2017 / 12$ & $\begin{array}{l}\text { Yorkshire and the } \\
\text { Humber }\end{array}$ & 2017 & April & $\begin{array}{l}\text { Open farm, same } \\
\text { premises as } \\
2017 / 12\end{array}$ & $5(5)$ & $\begin{array}{l}\text { C. parvum } \\
\text { IlaA17G1R1 }\end{array}$ & $\begin{array}{l}\text { Lambs (C. parvum } \\
\text { IlaA17G1R1, C. par- } \\
\text { vum and C. xiaoi) }\end{array}$ \\
\hline 170 & Wales & 2017 & April & Open farm & $7(7)$ & $\begin{array}{l}\text { C. parvum } \\
\text { IlaA15G2R1 }\end{array}$ & $\begin{array}{l}\text { Lambs (C. parvum } \\
\text { IlaA15G2R1) }\end{array}$ \\
\hline $2012 / 22$ & Wales & 2012 & March & $\begin{array}{l}\text { Open farm (com- } \\
\text { munity farm) }\end{array}$ & $15(10)$ & $\begin{array}{l}\text { C. parvum } \\
\text { IlaA15G2R1 }\end{array}$ & $\begin{array}{l}\text { Droppings from co- } \\
\text { penned lambs and } \\
\text { goats (C. parvum } \\
\text { IlaA15G2R1) }\end{array}$ \\
\hline 2009/19 & North-West & 2009 & May & $\begin{array}{l}\text { Commercial farm } \\
\text { (open day) }\end{array}$ & $155(41)$ & $\begin{array}{l}\text { C. parvum } \\
\text { IlaA17G1R1 }\end{array}$ & $\begin{array}{l}\text { Calves (C. parvum } \\
\text { IlaA17G1R1); } \\
\text { goats (C. parvum } \\
\text { IlaA17G1R1 and C. } \\
\text { xiaoi) }\end{array}$ \\
\hline $2016 / 24$ & Wales & 2016 & March & $\begin{array}{l}\text { Agricultural College } \\
\text { farm }\end{array}$ & $24(17)$ & $\begin{array}{l}\text { C. parvum } \\
\text { IlaA15G2R1 }\end{array}$ & $\begin{array}{l}\text { Sheep and lambs (C. } \\
\text { parvum llaA15G2R1 } \\
\text { and C. xiaoi) }\end{array}$ \\
\hline \multicolumn{8}{|l|}{ Drinking water } \\
\hline 77 & South-West & 2013 & April & $\begin{array}{l}\text { Mains drinking } \\
\text { water }\end{array}$ & $23(23)$ & $\begin{array}{l}\text { C. hominis IbA10G2 } \\
\text { and IdA18 }\end{array}$ & $\begin{array}{l}\text { C. hominis IbA10G2, } \\
\text { C. parvum and C. } \\
\text { andersoni in source } \\
\text { waters; C. hominis } \\
\text { and a gastric spe- } \\
\text { cies in treated water }\end{array}$ \\
\hline \multicolumn{8}{|l|}{ Food-borne } \\
\hline 78 & $\begin{array}{l}\text { Yorkshire and the } \\
\text { Humber }\end{array}$ & 2013 & April & $\begin{array}{l}\text { Milk from an } \\
\text { on-farm dairy, } \\
\text { pasteurisation } \\
\text { problems }\end{array}$ & $11(6)$ & $\begin{array}{l}\text { C. parvum } \\
\text { IlaA15G1R1 }\end{array}$ & $\begin{array}{l}\text { Calf (C. parvum } \\
\text { IlaA15G1R1) }\end{array}$ \\
\hline
\end{tabular}

a See Additional file 1: Table S1

have not been reported in outbreaks elsewhere. Subtype IIaA26G1R1 was a new finding with no previous reports. In two recreational water outbreaks two $C$. hominis subtypes were identified in different patients (Fig. 2b), indicating multiple contamination events.

Four $g p 60$ subtypes were identified in the five of the six C. parvum outbreaks linked to recreational waters. Two outbreaks were caused by the common IIaA15G2R1, and three involved subtypes that were not found in animal contact outbreaks; IIaA15R1 is a rarely reported subtype, IIdA17G1 caused a food-borne outbreak in Finland [26] and IIaA26G1R1 has not been reported previously.

Cryptosporidium is not a routine test parameter for recreational waters and sampling and testing can be difficult to arrange, is expensive and not always warranted [27]. Nevertheless, Cryptosporidium oocysts were detected in samples from 11 (13\%) outbreak premises.
Not all were submitted for genotyping, but in four outbreaks the oocysts were confirmed as C. hominis, of which three were subtyped and found to be IbA10G2. No other Cryptosporidium species or subtypes were found.

One of the two drinking water outbreaks involved a mains water supply, and consumers became infected with $C$. hominis IbA10G2 and IdA18; C. hominis was confirmed in the water supply but $g p 60$ sequences were not obtained. Both subtypes have been implicated in drinking water-related outbreaks previously $[9,28]$. The other drinking water outbreak was caused by $C$. parvum IIaA15G2R1 and was related to holiday cottages on a private water supply which was not sampled for Cryptosporidium.

Three of the four outbreaks linked to person-person spread were caused by $C$. hominis and one was not genotyped. In one outbreak, IbA10G2 was confirmed in 
patients. Three of the four environmental contact-related outbreaks were caused by C. parvum and one was not genotyped. Samples from only one were subtyped, with a rare subtype, IIaA21G4R1, identified among a group of soldiers after a military exercise in a rural area. Of nine outbreaks with no clear exposure, four were $C$. hominis (three IbA10G2, one not subtyped), three C. parvum (two IIaA15G2R1 and one IIaA17G1R1), one involved both species but not subtyped and in the other outbreak, no case samples were sent for typing.

Representative gp60 sequences from the outbreaks described here have been deposited into GenBank under accession numbers MK391438-MK391457, KF287126 and KT634306.

\section{Discussion}

We analysed a combined dataset of 178 outbreaks from voluntary notifications to eFOSS and those that came to the attention of the CRU during outbreak investigations. In England and Wales, there is no legal obligation to report outbreaks apart from those that are considered food-borne [29]. All surveillance systems are subject to underreporting, and eFOSS is no exception as it relies upon the voluntary participation of a wide range of professional groups and organisations for it to function effectively. National surveillance systems should therefore be streamlined as far as possible to make it easier for lead investigators to notify and report conclusions of their outbreak investigations, and the effectiveness of these systems should be reviewed on a regular basis. Once an outbreak has been identified and PHE alerted, the rate of return of eFOSS forms has been reported to be $80 \%$ [30], so further encouragement of lead investigators to notify the outbreak initially would lead to an improvement in reporting.

The most common vehicle of Cryptosporidium outbreaks was recreational water, especially swimming pools. This concurs with previous findings, and Cryptosporidium is the predominant aetiology of infectious disease linked to treated recreational water venues in England and Wales [31] and the USA [32]. There are difficulties and inadequacies in preventing contamination and treating pool water to disinfect and remove this small, chlorine-resistant parasite [33]. The Pool Water Treatment Advisory Group has published guideline standards for swimming pools [34, 35], and previous analysis of swimming pool-related outbreaks in England and Wales identified failures across the operation and management of pools [36]. Although there is no requirement for compliance assessment for swimming pools in the UK, a check list to identify failures as part of the acute response to outbreaks is available [34]. Systematic route cause analysis of outbreaks could direct efforts for further improvement.

Where identified, outbreaks were caused by C. parvum or $C$. hominis. The only other species reported to have caused an outbreak in England and Wales was Cryptosporidium cuniculus which caused a mains drinking water outbreak in 2008 [37]. Encouraging all laboratories to send Cryptosporidium-positive stools for identification and subtyping would ensure more outbreaks were characterised, and may assist in outbreak identification through more sensitive exceedance monitoring. The IIdA24G1 outbreak was large, widespread, and linked epidemiologically to food-borne transmission. It was identified initially through surveillance activities, and the epidemiology refined by identification of this unusual gp60 subtype, which helped identify cases from background and put a time frame on the outbreak. Exceedance monitoring may be improved by more extensive application and inclusion of species and subtyping data in routine surveillance data capture and this is currently in development.

The seasonal distribution of outbreaks was remarkably similar to that of sporadic cases, with C. parvum being most prevalent in the spring and $C$. hominis in the autumn [13], indicating there may be unrecognised outbreaks, and a burden of sporadic illness, linked to similar seasonal exposures. Although there were only four outbreaks attributed to person-to-person spread, usually in child daycare centres, all were in October and the effect of mixing children together after the summer holidays should be investigated further as a driver for seasonal increase in sporadic cases.

The preponderance of swimming pool-related outbreaks caused by $C$. hominis, and animal-contact related outbreaks caused exclusively by C. parvum, concurs with earlier reports $[17,18]$ and reflects the source of oocysts in each. Despite occasional reports of $C$. hominis infections in animals, their role in human infection is currently unclear [38]. There seems to be little evidence from epidemiological studies for animal involvement in human transmission of this species in England and Wales [10, 11 , and C. hominis was not found when sampling animals at premises associated with human outbreaks in this study. Zoonotic species other than C. parvum, such as $C$. ubiquitum, were found in animals but were not identified in outbreak-related cases.

Although few in number, the largest outbreaks were food-borne, and highlights the emergence of food, especially ready-to-eat salad leaves, as a vehicle. That foodborne outbreaks were caused by C. parvum is indicative of animal sources, most likely during production. Unlike drinking water, where implementation of improved catchment and source water protection, monitoring, 
and water treatment has reduced the number and size of water-borne Cryptosporidium outbreaks [39], fewer controls have been implemented in the food chain [40]. Likewise, there is a need to further control contamination and dispersal of Cryptosporidium through swimming pools, where not only the number of outbreaks but also the finding of unusual genotypes illustrates their potential for transmission. In the USA, the rapid emergence and spread of a virulent subtype (IaA28R4) in 2008 was linked to dispersal through swimming pools [41]. Although now more common than IbA10G2 in the USA, this subtype has yet to emerge in England and Wales.

The "hypertransmissible" subtype IIaA15G2R1 that caused most $C$. parvum outbreaks has been reported commonly in sporadic and outbreak cases and in a wide range of livestock, wild and other animals especially cattle [38]. There is much emphasis on sampling cattle as a host for C. parvum but small ruminants such as lambs can also be an important zoonotic source in some settings, especially open/petting farms [42]. However, genetic subpopulations overlap between IIaA15G2R1 and other gp 60 subtypes [16,38], and a multilocus genotyping scheme would provide further molecular epidemiological refinement [43]. Undoubtedly other gp60 subtypes cause human infection and outbreaks, but their lack of detection is most likely due to the lack of both case and outbreak surveillance globally. If all samples were subtyped (especially using a mutlilocus scheme) we would probably see greater diversity, and detect more outbreaks.

The proportion of outbreaks where suspected source material that was investigated to identify the Cryptosporidium spp. in recreational water and animal contact outbreaks (13\% and $16 \%$ respectively) was comparable to that reported for food-borne outbreaks caused by other pathogens where microbiological results were reported as providing evidence supporting the conclusions of the outbreak control team $[44,45]$. However, food items were not tested in the outbreaks reported here. Sampling and testing food such as ready-to-eat salad leaves is challenging: retrieving appropriate samples may be impossible as by the time the outbreak is identified none of the food remains for testing, and although there is an ISO standard for testing leafy greens for Cryptosporidium [8], we are not aware of any laboratories in the UK that hold accreditation for this test. Although there is no standard method for testing milk, sampling the calves on the farm where the implicated milk was produced and processed provided a microbiological link between the cases and the herd. Sampling source animals has greater potential to yield pathogens such as Cryptosporidium than sampling foods or the environment.

The public health benefit of identifying infecting Cryptosporidium species and subtypes in outbreak-associated cases is two-fold: (i) identifying and strengthening epidemiologic links between cases; and (ii) indicating possible exposures and outbreak sources. If meaningful samples are available from the latter then there are added benefits, but especially for food these are rarely available and standard methods for detection are lacking or not implemented. Linking cases with each other, refining epidemiology is especially useful in outbreaks identified by exceedence monitoring where clear epidemiological links do not readily emerge from existing data. To better understand the epidemiology of Cryptosporidium, molecular characterisation of Cryptosporidium specimens needs to shift from predominantly supporting outbreak investigations to becoming nationally systematic.

\section{Conclusions}

The degree to which Cryptosporidium outbreaks are unreported is not known but identified trends may reflect the primary vehicles or settings of transmission. Improved outbreak reporting needs to be enabled, and route cause analysis used to identify measures for reductions in exposure. Characterisation of Cryptosporidium spp. and subtypes needs to shift from predominantly supporting outbreak investigations to becoming nationally systematic, enabling more sensitive and specific exceedence monitoring and identification of large scale outbreaks that may not be geographically defined. This is an emerging trend and has been seen with foodborne outbreaks. More discriminatory, multilocus subtyping should be implemented to investigate cases and outbreaks.

\section{Methods}

The aim was to describe and analyse trends in the Cryptosporidium species and gp60 genotypes identified in human outbreaks of cryptosporidiosis in England and Wales from January 2009 to December 2017. Definitions used to define an outbreak were: an incident in which two or more people experienced a similar illness and linked in time or place, or a greater than expected rate of Cryptosporidium reports compared with the usual background rate for a place and time. Cryptosporidium outbreaks were extracted from the eFOSS database and from records for those that also came to the attention of the national CRU during outbreak investigations. The proportions of outbreak routes of transmission were compared between the two databases by uncorrected $C$ Chi square and a $P$-value of 0.05 was regarded as significant. The databases were reconciled by PHE centre, setting/place name, postcode, dates of first and last known cases, and populated with Cryptosporidium species and gp60 subtypes identified in the stools of cases and any 
additional samples tested. The outbreaks were analysed for trends in vehicles and settings, season, and associated Cryptosporidium species and gp60 subtypes. The CRU archive and the NCBI nucleotide DB and PubMed were searched for previous reports of subtypes found.

To identify species, Cryptosporidium positive stools were sent by primary diagnostic laboratories to the national CRU, generally within 5 days of collection [13]. Oocysts were separated from faecal material by salt flotation, disrupted by boiling, and DNA extracted using proteinase $\mathrm{K}$ digestion and a spin column kit (QIAamp DNA mini kit, Qiagen, Hilden, Germany) as described previously [13]. Samples were screened for C. parvum and C. hominis using a duplex real-time PCR assay [46] and other species were sought using a nested PCR targeting the SSU rDNA gene [47]. A nested PCR targeting the gp60 gene was used to subtype C. parvum and C. hominis samples known or suspected to be part of outbreaks as described previously [48]; to simplify workflow a cocktail of single round PCR primers was developed and used from 2015, as described previously [49]. PCR amplicons were subjected to bidirectional sequencing (Applied Biosystems $3500 \mathrm{XL}$ ) and sequence similarities searched for in the NCBI Blastn website tools. Gp60 subtypes were confirmed by manual identification of trinucleotide repeats and other repeat sequences (Fig. 1). The findings were contextualised at the time to inform outbreak investigations and updated for this article.

In animal contact outbreaks, animals were sampled by a Veterinary Investigation Officer if requested by the outbreak control team and tested using immunofluorescence microscopy (Crypto-cel, Cellabs) at the Animal and Plant Health Agency's central laboratory, Weybridge. Cryptosporidium-positive samples were sent to the CRU for genotyping as described above. In recreational and drinking water outbreaks, sampling and testing was undertaken as described in [7] if requested by the outbreak control team. Cryptosporidium positive microscope slides sent to the CRU for genotyping were processed as described previously [37] until 2015. After 2015 DNA extraction from slides was done using a chelex-based method as described previously [50].

\section{Additional file}

Additional file 1: Table S1. A database of 178 Cryptosporidium outbreaks in England and Wales, 2009-2017.

\section{Abbreviations}

CRU: Cryptosporidium Reference Unit; eFOSS: Outbreak Electronic Foodborne and Non-Foodborne Gastrointestinal Outbreak Surveillance System; gp60: 60 kDa glycoprotein; PHE: Public Health England.

\section{Acknowledgements}

We thank Florence Aromona for providing the eFOSS data, staff at the national Cryptosporidium Reference Unit for genotyping isolates, and members of outbreak control teams for investigating and reporting outbreaks. RE is affiliated to the National Institute for Health Research Health Protection Research Unit (NIHR HPRU) in Gastrointestinal Infections at University of Liverpool in partnership with Public Health England (PHE), in collaboration with University of East Anglia, University of Oxford and the Institute of Food Research. The views expressed are those of the authors and not necessarily those of the NHS, the NIHR, the Department of Health, Public Health England or Public Health Wales.

\section{Funding}

This study was funded jointly by Public Health Wales and Public Health England as part of core activities for the investigation and management of cryptosporidiosis.

\section{Availability of data and materials}

The data that support the findings of this study are available from Public Health England but restrictions apply to the availability of these data, which were used under license for the current study, and so are not publicly available. Data are however available from the authors upon reasonable request and with permission of Public Health England.

\section{Authors' contributions}

$\mathrm{RC}$ devised and undertook the study and analysis and was a major contributor to the manuscript. GR and KE performed the species identification, gp60 analysis and interpretation, and contributed to writing the manuscript. RE provided the eFOSS data and was a major contributor in writing the manuscript. All authors read and approved the final manuscript.

Ethics approval and consent to participate

Not applicable.

\section{Consent for publication}

Not applicable.

\section{Competing interests}

The authors declare that they have no competing interests.

\section{Publisher's Note}

Springer Nature remains neutral with regard to jurisdictional claims in published maps and institutional affiliations.

\section{Author details}

${ }^{1}$ Cryptosporidium Reference Unit, Public Health Wales Microbiology and Health Protection, Singleton Hospital, Swansea SA2 8QA, UK. ${ }^{2}$ Swansea University Medical School, Swansea University, Grove Building, Singleton Park, Swansea SA2 8PP, UK. ${ }^{3}$ National Infection Service, Public Health England, 61, Colindale Avenue, London, UK. ${ }^{4}$ National Institute for Health Research Health Protection Research Unit (NIHR HPRU) in Gastrointestinal Infections, Liverpool, UK.

Received: 19 November 2018 Accepted: 26 February 2019

Published online: 12 March 2019

References

1. The Health Protection (Notification) Regulations 2010 Schedule 2 causative agents. http://www.legislation.gov.uk/uksi/2010/659/contents/made. Accessed 25 Sept 2018.

2. Anon. Cryptosporidium spp. data 2007 to 2016 National laboratory data for residents of England and Wales, PHE, May 2018. https://assets.publi shing.service.gov.uk/government/uploads/system/uploads/attachment_ data/file/711919/cryptosporidium_spp_data_2007_to_2016_may_2018. pdf. Accessed 25 Sept 2018.

3. Noufaily A, Enki DG, Farrington P, Garthwaite P, Andrews N, Charlett A. An improved algorithm for outbreak detection in multiple surveillance systems. Stat Med. 2013;32:1206-22. 
4. Chalmers RM, McCarthy N, Barlow KL, Stiff R. An evaluation of health protection practices for the investigation and management of Cryptosporidium in England and Wales. J Public Health. 2016;40:114-20.

5. Cacciò SM, Chalmers RM. Human cryptosporidiosis in Europe. Clin Microbiol Infect. 2016;22:471-80.

6. International Standards Organisation. ISO 15553:2006. Water quality - isolation of Cryptosporidium oocysts and Giardia cysts from water. Geneva: ISO; 2006.

7. Environment Agency. The microbiology of drinking water. 2010: part 14 Methods for the isolation, identification and enumeration of Cryptosporidium oocysts and Giardia cysts. London: EA; 2010.

8. International Standards Organisation. ISO 18744:2013. Microbiology of the food chain - detection and enumeration of Cryptosporidium and Giardia in fresh leafy green vegetables and berry fruits. Geneva: ISO; 2013.

9. Xiao L, Feng Y. Molecular epidemiologic tools for waterborne pathogens Cryptosporidium spp. and Giardia duodenalis. Food Waterborne Parasitol. 2017;8-9:14-32.

10. Hunter PR, Hughes LS, Woodhouse S, Syed Q, Verlander N, Chalmers RM, et al. Case-control study of sporadic cryptosporidiosis with genotyping. Emerg Infect Dis. 2004;10:1241-9.

11. Lake IR, Harrison FCD, Chalmers RM, Bentham G, Nichols G, Hunter PR, et al. Case-control study of environmental and social factors influencing cryptosporidiosis. Eur J Epidemiol. 2007;22:805-11.

12. Xiao L. Molecular epidemiology of cryptosporidiosis: an update. Exp Parasitol. 2010;124:80-9.

13. Chalmers RM, Elwin K, Thomas AL, Guy EC, Mason B. Long-term Cryptosporidium typing reveals the aetiology and species-specific epidemiology of human cryptosporidiosis in England and Wales, 2000 to 2003. Euro Surveill. 2009;14:19086.

14. Strong WB, Gut J, Nelson RG. Cloning and sequence analysis of a highly polymorphic Cryptosporidium parvum gene encoding a 60-kilodalton glycoprotein and characterization of its 15- and 45-kilodalton zoite surface antigen products. Infect Immun. 2000;68:4117-34.

15. Cama VA, Ross JM, Crawford S, Kawai V, Chavez-Valdez R, Vargas D, et al. Differences in clinical manifestations among Cryptosporidium species and subtypes in HIV-infected persons. J Infect Dis. 2007;196:684-91.

16. Sulaiman IM, Hira PR, Zhou L, Al-Ali FM, Al-Shelahi FA, Shweiki HM, et al. Unique endemicity of cryptosporidiosis in children in Kuwait. J Clin Microbiol. 2005;43:2805-9.

17. Chalmers RM. Waterborne cryptosporidiosis outbreaks. Ann I Super Sanità. 2012;48:429-46.

18. Chalmers RM, Giles M. Zoonotic cryptosporidiosis in the UK - challenges for control. J Appl Microbiol. 2010;109:1487-97.

19. Deshpande AP, Jones BL, Connelly L, Pollock KG, Brownlie S, Alexander CL. Molecular characterization of Cryptosporidium parvum isolates from human cryptosporidiosis cases in Scotland. Parasitology. 2015;142:318-25

20. Mahon M, Doyle S. Waterborne outbreak of cryptosporidiosis in the South East of Ireland: weighing up the evidence. Ir J Med Sci. 2017; 186:989-94.

21. Gherasim A, Lebbad M, Insulander M, Decraene V, Kling A, Hjertqvist M, et al. Two geographically separated food-borne outbreaks in Sweden linked by an unusual Cryptosporidium parvum subtype, October 2010. Euro Surveill. 2012;17:20318.

22. Kinross P, Beser J, Troell K, Axén C, Björkman C, Lebbad M, et al. Cryptosporidium parvum infections in a cohort of veterinary students in Sweden. Epidemiol Infect. 2015;143:2748-56.

23. Utsi L, Smith SJ, Chalmers RM, Padfield S. An outbreak of a rare Cryptosporidium parvum subtype in visitors to an industry-compliant petting farm in the UK: a case-control study. Epidemiol Infect. 2016;144:1000-9.

24. McKerr C, Adak G, Nichols G, Gorton R, Chalmers RM, Kafatos G, et al. An outbreak of Cryptosporidium parvum across England \& Scotland associated with consumption of fresh pre-cut salad leaves, May 2012. PLoS One 2015:10:e0125955.

25. Public Health England. National increase of Cryptosporidium parvum, 2015. Final outbreak investigation report. London: Public Health England; 2017

26. Åberg R, Sjöman M, Hemminki K, Pirnes A, Räsänen S, Kalanti A, et al. Cryptosporidium parvum caused a large outbreak linked to frisée salad in Finland, 2012. Zoonoses Public Health. 2015;62:618-24.
27. Anon. Guidance for the investigation of Cryptosporidium linked to swimming pools; 2011. http://www.wales.nhs.uk/sites3/page.cfm?orgid $=457 \&$ pid $=49029$. Accessed 25 Sept 2018 .

28. Chalmers RM, Robinson G, Elwin K, Hadfield SJ, Thomas E, Watkins J, et al. Detection of Cryptosporidium species and sources of contamination with Cryptosporidium hominis during a waterborne outbreak in north west Wales. J Water Health. 2010;8:311-25.

29. European Food Safety Authority. Update of the technical specifications for harmonised reporting of food-borne outbreaks through the European Union reporting system in accordance with Directive 2003/99/EC. EFSA J. 2014;12:3598.

30. Hughes C, Gillespie IA, O'Brien SJ. Foodborne transmission of infectious intestinal disease in England and Wales, 1992-2003. Food Control. 2007:18:766-72.

31. Smith A, Reacher M, Smerdon W, Adak GK, Nichols G, Chalmers RM. Outbreaks of waterborne infectious intestinal disease in England and Wales, 1992-2003. Epidemiol Infect. 2006;134:1141-9.

32. Hlavsa MC, Cikesh BL, Roberts VA, Kahler AM, Vigar M, Hilborn ED, et al. Outbreaks associated with treated recreational water - United States, 2000-2014. MMWR-Morbid Mortal W. 2018;67:547-51.

33. Chalmers RM, Johnston R. Understanding the public health risks of Cryptosporidium in swimming pools: a transmission pathway approach. Perspect Public Heal. 2018;138:238-40.

34. Anon. Swimming pool water treatment and quality standards for pools and spas. Tamworth: PWTAG Ltd; 2017.

35. The PWTAG Code of Practice. https://www.pwtag.org.uk/knowledge/ code of practice.php. Accessed 25 Sept 2018.

36. Chalmers RM. Review of outbreaks of cryptosporidiosis in swimming pools. Final report to drinking water inspectorate, contract number DWI 70/2/131, DEFRA, London; 2001. http://dwi.defra.gov.uk/research/compl eted-research/reports/DWI70_2_131_swimming\%20pools.pdf. Accessed 25 Sept 2018

37. Chalmers RM, Robinson G, Elwin K, Xiao L, Ryan U, Modha D, et al. Cryptosporidium rabbit genotype, a newly identified human pathogen. Emerg Infect Dis. 2009:15:829-30.

38. Feng Y, Ryan UM, Xiao L. Genetic diversity and population structure of Cryptosporidium. Trends Parasitol. 2018;34:997-1011.

39. Lloyd A, Drury D. Continuous monitoring for Cryptosporidium - a novel approach to public health protection. Water Sci Technol. 2002:46:297-301.

40. EFSA Panel on Biological Hazards (BIOHAZ), Koutsoumanis K, Allende A, Alvarez-Ordóñez A, Bolton D, Bover-Cid S, Chemaly M, et al. Public health risks associated with foodborne parasites. EFSA J. 2018;16:5495-608.

41. Feng $Y$, Tiao N, Li N, Hlavsa M, Xiao L. Multilocus sequence typing of an emerging Cryptosporidium hominis subtype in the United States. J Clin Microbiol. 2014;52:524-30.

42. Gormley FJ, Little CL, Chalmers RM, Rawal N, Adak GK. Zoonotic cryptosporidiosis from petting farms, England and Wales, 1992-2009. Emerg Infect Dis. 2011;17:151-2.

43. Chalmers RM, Pérez-Cordón G, Cacció SM, Klotz C, Robertson LJ, on behalf of the participants of the Cryptosporidium genotyping workshop (EURO-FBP). Cryptosporidium genotyping in Europe: the current status and processes for a harmonised multi-locus genotyping scheme. Exp Parasitol. 2018;191:25-30.

44. O'Brien SJ, Elson R, Gillespie IA, Adak GK, Cowden JM. Surveillance of foodborne outbreaks of infectious intestinal disease in England and Wales 1992-1999: contributing to evidence-based food policy? Public Health. 2002;116:75-80.

45. Gormley FJ, Little CL, Rawal N, Gillespie IA, Lebaigue S, Adak GK. A 17-year review of foodborne outbreaks: describing the continuing decline in England and Wales (1992-2008). Epidemiol Infect. 2011;139:688-99.

46. Moore CE, Elwin K, Phot N, Seng C, Mao S, Suy K, et al. Molecular characterisation of Cryptosporidium species and Giardia duodenalis from symptomatic Cambodian children. PLoS Negl Trop Dis. 2016;10:e0004822.

47. Jiang J, Alderisio KA, Xiao L. Distribution of Cryptosporidium genotypes in storm event water samples from three watersheds in New York. Appl Environ Microbiol. 2005;71:4446-54

48. Alves M, Xiao L, Sulaiman I, Lal AA, Matos O, Antunes F. Subgenotype analysis of Cryptosporidium isolates from humans, cattle, and zoo ruminants in Portugal. J Clin Microbiol. 2003:41:2744-7. 
49. Chalmers RM, Robinson G, Hotchkiss E, Alexander C, May S, Gilray J, et al. Suitability of loci for multiple-locus variable-number of tandem-repeats analysis of Cryptosporidium parvum for inter-laboratory surveillance and outbreak investigations. Parasitology. 2017;144:37-47.
50. Di Giovanni GD, Hoffman RM, Sturbaum GD. Cryptosporidium genotyping method for regulatory microscope slides. Water Research Foundation. Web Report: \#4099; 2010. http://www.waterrforg/Pages/Projects. aspx?PID=4099. Accessed 25 Sept 2018.
Ready to submit your research? Choose BMC and benefit from:

- fast, convenient online submission

- thorough peer review by experienced researchers in your field

- rapid publication on acceptance

- support for research data, including large and complex data types

- gold Open Access which fosters wider collaboration and increased citations

- maximum visibility for your research: over $100 \mathrm{M}$ website views per year

At BMC, research is always in progress.

Learn more biomedcentral.com/submissions 